\title{
Cross-talks of Sensory Transcription Networks in Response to Various Environmental Stresses
}

\author{
Ting CHEN ${ }^{1}$, Feng $\mathrm{LI}^{2}$, Bor-Sen CHEN ${ }^{2 *}$ \\ ${ }^{1}$ (Department of Electronic Engineering, Fudan University, Shanghai 200433, China) \\ ${ }^{2}$ (Department of Electrical Engineering and Computer Science, National Tsing Hua University, Hsinchu 300, Taiwan)
}

Erratum to Interdiscip Sci Comput Life Sci (2009) 1: 46-54

DOI: $10.1007 / \mathrm{s} 12539-008-0018-1$

The original version of this article unfortunately contained a mistake. The second author, Feng Li's affiliation was incorrect in the paper version and the HTML version of this article. The correct information is: Department of Electronic Engineering, Fudan University, Shanghai 200433, China.

The online version of the original article can be found at http://dx.doi.org/10.1007/s12539-008-0018-1.

\footnotetext{
*Corresponding author.

E-mail: bschen@ee.nthu.edu.tw
} 